\title{
SV40 large T immortalised cell lines of the rat blood-brain and blood-retinal barriers retain their phenotypic and immunological characteristics
}

\author{
J. Greenwood ${ }^{\text {a }}{ }^{*}$, G. Pryce ${ }^{\text {a }}$, L. Devine ${ }^{\text {a }}$, D.K. Male ${ }^{\text {b }}$, W.L.C. dos Santos ${ }^{\text {b }}$, V.L. Calder ${ }^{\text {a }}$, \\ P. Adamson ${ }^{a}$ \\ ${ }^{a}$ Department of Clinical Ophthalmology, Institute of Ophthalmology, University College London, Bath Street, London ECIV $9 E L, U K$ \\ ${ }^{\mathrm{b}}$ Department of Neuropathology, Institute of Psychiatry, DeCrespigny Park, London SE5 8AF, UK
}

Received 17 May 1996; revised 20 June 1996; accepted 24 June 1996

\begin{abstract}
In the central nervous system the blood-brain and blood-retinal barriers (BBB and BRB respectively) are instrumental in maintaining homeostasis of the neural parenchyma and controlling leucocyte traffic. These cellular barriers are formed primarily by the vascular endothelium of the brain and retina although in the latter the pigmented epithelial cells also form part of the barrier. From primary cultures of rat brain endothelium, retinal endothelium and retinal pigment epithelium (RPE) we have generated temperature sensitive SV40 large T immortalised cell lines. Clones of brain (GP8.3) and retinal (JG2.1) endothelia and RPE (LD7.4) have been derived from parent lines that express the large $\mathrm{T}$ antigen at the permissive temperature. The endothelial cell (EC) lines expressed P-glycoprotein, GLUT-1, the transferrin receptor, von Willebrand factor and the RECA-1 antigen and exhibited high affinity uptake of acetylated LDL and stained positive with the lectin Griffonia simplicifolia. The RPE cell line was positive for cytokeratins and for the rat RPE antigen RET-PE2. All the cell lines expressed major histocompatibility complex (MHC) class 1 and intercellular adhesion molecule (ICAM)-1 constitutively and could be induced to express MHC class II and vascular cell adhesion molecule (VCAM)- 1 following cytokine activation. The EC also expressed platelet endothelial cell adhesion molecule (PECAM)-1. Monolayers of these cells could support the migration of antigen-specific $T$ cell lines. The generation of immortalised cell lines derived from the rat BBB and BRB should prove to be useful tools for the study of these specialised cellular barriers.
\end{abstract}

Keywords: Blood-brain barrier; Blood-retinal barrier; Endothelium; Immortalisation; Retinal pigment epithelium

\section{Introduction}

The blood-brain (BBB) and blood-retinal (BRB) barriers form a selective cellular interface between the blood and the central nervous system (CNS). These barriers are important in controlling the passage of molecules and cells to and from the neural parenchyma and thus in maintaining homeostasis. In the brain, the endothelial cells of the cerebral vasculature that constitute the $\mathrm{BBB}$, form tight intercellular junctions which, in conjunction with minimal pinocytosis and a lack of pores, leads to impermeable vessels with very high electrical resistance's (Crone and Olesen, 1982; Butt and Jones, 1992). In the retina, the

\footnotetext{
* Corresponding author. Tel.: +44-171-6086858; fax: +44-1716086810; e-mail: j.greenwood@ucl.ac.uk
}

BRB is comprised of two distinct cell types that are separated anatomically. The retinal vascular endothelia, that feed the anterior portion of the retina, are thought to be identical to those of the brain (Greenwood, 1992a; Towler et al., 1994). The retinal pigment epithelium (RPE), however, overly the permeable vessels of the choroidal circulation and form the posterior barrier by virtue of their tight apical junctions and in this respect are similar to the tight epithelial cells of the choroid plexus. Together these two cell types constitute the BRB.

It is clear that the specialised properties of CNS endothelia is not restricted to the expression of tight junctions and the formation of a physical barrier. Other properties of the endothelia also contribute to the specialised nature of the barrier, in particular the unique distribution and expression of many surface molecules that are absent on endothelia from other organs. This can be exemplified 
by the expression of molecules such as the high affinity glucose transporter (GLUT-1), the transferrin receptor and the product of the multidrug resistance gene, P-glycoprotein (Pgp) as well as the absence of other antigens which are expressed on non-CNS endothelia such as OX-43 (in the rat) and PAL-E (in humans).

Endothelia from the brain and retina also differ from peripheral endothelia in their ability to capture circulating leucocytes, being considerably less adhesive than non-CNS vascular beds (Hughes et al., 1988; Male et al., 1990; Wang et al., 1993). During immune-mediated diseases of the CNS, however, the vascular endothelia play a critical role in recruiting leucocytes from the circulation (Male et al., 1990, 1994; Greenwood and Calder, 1993; Greenwood et al., 1995; Calder and Greenwood, 1995; Devine et al., 1996a) and in influencing lymphocyte function (McCarron et al., 1985; Risau et al., 1990; Wang et al., 1995; Bourdoulous et al., 1995).

Both the normal and pathological functions of cells of the BBB and BRB have been the subject of a substantial amount of research. Until recently, most investigations were restricted to in vivo studies but, with the experimental flexibility offered by in vitro methods, techniques have been developed to isolate and culture CNS-derived endothelial cells (for reviews see Greenwood, 1991; Joó, 1996). These techniques, however, have proved to be both difficult and time consuming as CNS-derived endothelia and RPE are phenotypically unstable in long-term culture, remain impure and have low plating efficiency. As a result of this phenotypic instability, most investigations are confined to the use of primary cultures. Techniques are now available, however, to immortalise cells and the development of such cells from the BBB and BRB will be of considerable use in investigating the properties of these specialised cellular barriers. However, this approach will be of value only if the immortalised cells retain the characteristics of primary cultures over many passages or, if panels of different cell lines can be generated which together encompass the characteristics of primary cultures.

In a series of recent reports an immortalised rat brain endothelial cell line (RBE4) has been described that has proved to be a valuable resource for studying some of the properties of cerebral endothelia (Roux et al., 1994; Bourdoulous et al., 1995; Abbott et al., 1995). These cerebral endothelia, which were immortalised by transfection with pE1A-neo which encodes the adenovirus 2 E1A gene, retain many of their in vivo characteristics and are proving to be useful in a number of investigations. Similarly, there has also been a recent report of an SV40 large T immortalised RPE cell line (RPE-J) which retain many of the characteristics of RPE primary cultures (Nabi et al., 1993). However, since the techniques used to immortalise cells are based on random chromosomal integration and copy number of the immortalising gene, the resulting lines are likely to differentially reflect the characteristics of endothelial or RPE primary cultures. It is therefore important that further cell lines are produced so that those retaining particular characteristics can be identified.

Here we describe the development and characterisation of immortalised cells derived from primary cultures of both rat blood-brain and blood-retinal barriers using a temperature sensitive form of the SV40 large T antigen which has previously been used to immortalise rodent cells (Jat et al., 1986). The production of stable cell lines that retain many of the characteristics of primary cultures will be of great use to those investigating the properties of the blood-tissue barriers of the CNS including their important role in the pathogenesis of immune-mediated CNS disease.

\section{Materials and methods}

\subsection{Materials}

Rat recombinant IFN- $\gamma$ was obtained from Holland biotechnology BV (Leiden) and mouse TNF $\alpha$ was obtained from Genzyme (Kent). Mouse anti-rat intercellular adhesion molecule-1 (ICAM-1; 1A29) and mouse anti-rat platelet endothelial cell adhesion molecule-1 (PECAM-1; 3A12) monoclonal antibodies ( $\mathrm{mAbs}$ ) were obtained from Serotec (Oxford). The anti-rat vascular cell adhesion molecule-1 (VCAM-1; 5F10) was a generous gift from Dr. R. Lobb (Biogen, MA, USA). The anti-rat MHC class II I-A (OX-6) and MHC class II I-E (OX-17) mAbs were produced by culturing hybridoma cell lines which were a generous gift of Dr. M. Puklavec (MRC, Oxford). The anti-rat MHC class I mAb (OX-18), anti-rat transferrin receptor (OX-26), anti-rat endothelial mAb RECA-1 (Duijvestijn et al., 1992), anti-rat endothelial (non-CNS) mAb (OX-43), anti-rat CD44 (OX-50) and the FITCRAMIG, which was affinity purified and non-cross reactive with rat, were all obtained from Serotec. Anti-P-glycoprotein (JSB-1) was obtained from Sera-Lab (Sussex). Anti-rat-GLUT-1 mAb was obtained from Dunn Laboratories (Asbach, Germany). The FITC-labelled lectin Griffonia simplicifolia (Bandeiraea simplicifolia) was purchased from Sigma (Dorset). RET-PE2 mAb was a generous gift from Professor C. Barnstaple (Yale, USA). The cross reacting anti-human cytokeratin $\mathrm{mAb}(\mathrm{K} 8.13)$ was obtained from ICN Biomedicals, UK and rabbit anti-human von-Willibrand factor polyclonal $\mathrm{Ab}$ was obtained from Dako (Oxford). All other antibodies used were from a panel of $\mathrm{mAb}$ that stained rat brain endothelia in tissue sections and were obtained from tissue culture supernatants from hybridoma cell lines supplied by Dr. W. Hickey (Dartmouth Medical School, NH, USA). Acetylated low-density lipoprotein labelled with a fluorescent probe (Dil-Ac-LDL) was obtained from Biogenesis (Bournmouth). The SVU 19.5 SV40tsa58 producer cell line and the mouse anti-large $\mathrm{T}$-antigen $\mathrm{mAb}$ were generous gifts from Dr. P. Jat (Ludwig Institute, London). All other reagents were purchased from Sigma. 


\subsection{Animals}

Endothelial cells were derived from specific pathogen free (SPF) 4-6 week old female Lewis rats (Charles River, Kent). Retinal pigment epithelium (RPE) were isolated and grown from 6-8 day old SPF PVG $\left(\mathrm{RTI}^{\mathrm{c}}\right)$ rats bred in-house.

\subsection{Rat brain and retinal endothelium}

Endothelia from brain and retina were isolated and cultured as previously described (Greenwood, 1992b; Abbott et al., 1992). These techniques routinely produce primary cultures of $>95 \%$ purity. Briefly, rat retina or chopped cerebral cortex was dispersed by enzymatic digestion and microvessel fragments separated from other material and single cells by density dependent centrifugation on $25 \%$ bovine serum albumin and 50\% Percoll gradients. The microvessel fragments were washed and plated on to collagen (type 1) coated plastic tissue culture flasks. Growth media consisted of Ham's F-10 medium supplemented with $17.5 \%$ plasma derived serum (First Link Ltd., West Midlands, UK), $7.5 \mu \mathrm{g} / \mathrm{ml}$ endothelial cell growth supplement (First Link Ltd.), $80 \mu \mathrm{g} / \mathrm{ml}$ heparin, $2 \mathrm{mM}$ glutamine, $0.5 \mu \mathrm{g} / \mathrm{ml}$ vitamin $\mathrm{C}, 100 \mathrm{U} / \mathrm{ml}$ penicillin and $100 \mu \mathrm{g} / \mathrm{ml}$ streptomycin. The cultures were maintained at $37^{\circ} \mathrm{C}$ in $5 \% \mathrm{CO}_{2}$ and media replaced every 3 days until the formation of monolayers. Primary cultures of endothelial cells from both brain and retina were positive for the expression of von Willebrand factor and the uptake of acetylated-LDL.

\subsection{Rat retinal pigment epithelium}

RPE were isolated from 6-8 day old PVG rats according to the method of Chang et al. (1991). Briefly, eyes were enucleated and the intact globes digested with $2 \%$ dispase for $30 \mathrm{~min}$. The eyes were then dissected to remove the cornea, lens and vitreous, and the retina carefully isolated and incubated for a further $15 \mathrm{~min}$ in Ham's F-10 supplemented with $20 \%$ foetal calf serum, $20 \mathrm{mM}$ HEPES, $7.5 \%$ sodium bicarbonate, $2 \mathrm{mM}$ glutamine, 100 $\mathrm{U} / \mathrm{ml}$ penicillin and $100 \mu \mathrm{g} / \mathrm{ml}$ streptomycin. After incubation, sheets of RPE cells were separated from the neuroretina and trypsinised to obtain a single cell suspension. The cells were plated and grown in $25 \mathrm{~cm}^{2}$ tissue culture flasks to semi-confluence. Primary cultures were pigmented and positive for cytokeratin and the rat RPEspecific epitope RET-PE2 (Neill and Barnstable, 1990; Devine et al., 1996a).

\subsection{Rat aortic endothelium}

Aortic endothelium was isolated by the method described by McGuire and Orkin (1987). Rat aorta was removed by dissection, cut into small pieces $(2-5 \mathrm{~mm})$ and placed luminal side down onto collagen-coated 24 well plates and cultured in RPMI supplemented with $20 \%$ foetal calf serum, $7.5 \mu \mathrm{g} / \mathrm{ml}$ endothelial cell growth supplement (First Link Ltd.), $80 \mu \mathrm{g} / \mathrm{ml}$ heparin, $2 \mathrm{mM}$ glutamine, 0.5 $\mu \mathrm{g} / \mathrm{ml}$ vitamin C, $100 \mathrm{U} / \mathrm{ml}$ penicillin and $100 \mu \mathrm{g} / \mathrm{ml}$ streptomycin. After 3 days the explants were removed and outgrowing cells were expanded and passaged by trypsinisation. At confluence the cells had the 'cobblestone' morphology characteristic of large vessel endothelium, expressed von Willebrand factor and grew in medium containing D-valine (a capacity lacking in fibroblasts and smooth muscle cells). Cells were used after passage 3 which is the earliest stage at which sufficient cells were available for experimentation.

\section{6. $S$-Ag specific $C D 4^{+} T$ cell lines}

Lewis rat $\mathrm{T}$-cell lines specific for purified bovine retinal soluble antigen $(\mathrm{S}-\mathrm{Ag})$ were prepared as previously described (Sedgwick et al., 1989). Briefly, lymph nodes were collected from bovine S-Ag immunised rats and the lymphocytes propagated by periodically alternating antigen activation with IL-2 stimulation. The cell lines express the marker of the $\mathrm{CD}^{+} \mathrm{T}$ cell subset, are $\mathrm{CD} 45 \mathrm{Rc}^{\text {low }}$ and recognise S-Ag in the molecular context of MHC class II determinants (Zhao et al., 1994). These cells have previously been shown to be highly migratory across monolayers of primary culture brain and retinal endothelia (Greenwood and Calder, 1993; Greenwood et al., 1995) and RPE monolayers (Devine et al., 1996a,b).

\subsection{SV40 large $T$ immortalisation of brain and retinal endothelium and retinal pigment epithelium}

A replication deficient SV40 retrovirus was produced from the producer cell line SVU19.5 (a generous gift from Dr. P.S. Jat, Ludwig Institute, London, UK) in which a packaging defective mouse moloney leukaemia provirus was present. The retroviral vector encodes a temperature sensitive (tsa58), non-SV40-origin binding mutant of the large $\mathrm{T}$-antigen and a selectable neomycin resistance gene (aminoglycoside phosphotransferase I). The supernatant was passed through a $0.45 \mu \mathrm{m}$ filter to remove unwanted producer cells and added to primary cultures of endothelial or RPE cells previously plated 2-3 days prior to the transfection. $200 \mu 1$ of virus in $2 \mathrm{ml}$ of media containing 8 $\mu \mathrm{g} / \mathrm{ml}$ polybrene (Aldrich, Dorset) was added and incubated with cells for either $2 \mathrm{~h}$ (for RPE) or $4 \mathrm{~h}$ (for endothelia) at $37^{\circ} \mathrm{C}$ with gentle agitation. Incubation media was removed and $5 \mathrm{ml}$ of fresh medium added and cultured for $48 \mathrm{~h}$. Cells were then plated into selective media containing $200 \mu \mathrm{g} / \mathrm{ml} \mathrm{G} 418$ (geneticin, Gibco) and immortalised parent lines were obtained by selection of resistant colonies. Clones were acquired from parent lines by trypsinisation and plating into 96 well plates at a theoretical concentration of 0.33 cell per well. Several clones were 
expanded and on morphological criteria a single clone from each parent line was expanded for investigation.

\subsection{Detection of endothelial and epithelial cell antigens by ELISA, immunocytochemistry and flow cytometry}

\subsubsection{ELISA}

Rat brain and rat retinal endothelial cells (primary cultures and immortalised cells) and RPE were seeded at confluent density onto 96 well plates and cultured for 3 days before use in experiments. Untreated cells or cells treated with cytokines were washed four times in ice-cold Hanks buffered salt solution (HBSS) and fixed with $0.1 \%$ glutaraldehyde in phosphate buffered saline A (PBSA) for $10 \mathrm{~min}$ at room temperature. Aldehydes were subsequently quenched with $50 \mathrm{mM}$ Tris- $\mathrm{HCl}$, pH 7.5 for $20 \mathrm{~min}$ at room temperature. Primary antibodies against aldehyde-resistant antigens were diluted in $100 \mu \mathrm{l}$ HBSS containing $100 \mu \mathrm{g} / \mathrm{ml}$ normal rabbit $\mathrm{IgG}$ and $4 \mathrm{mg} / \mathrm{ml}$ bovine serum albumin and incubated with cells for $45 \mathrm{~min}$ at $37^{\circ} \mathrm{C}$. Cells were washed 4 times with PBSA containing $0.2 \%$ Tween20 and incubated with biotinylated-anti-mouse-IgG (1:700; Amersham) for $45 \mathrm{~min}$ at $37^{\circ} \mathrm{C}$. Cells were again washed 4 times with PBSA containing 0.2\% Tween-20 and incubated with streptavidin-horseradish peroxidase (1:700; Amersham) for $45 \mathrm{~min}$ at $37^{\circ} \mathrm{C}$. Cells were washed 4 times in PBSA containing $0.2 \%$ Tween- 20 and incubated with $100 \mu \mathrm{l}$ tetramethylbenzidine $(0.1 \mathrm{mg} / \mathrm{ml})$ and $0.03 \% \mathrm{H}_{2} \mathrm{O}_{2}$ in citrate-acetate buffer ( $\mathrm{pH} \mathrm{5)}$ for $10 \mathrm{~min}$. Reactions were stopped by the addition of $50 \mu \mathrm{l} 1 \mathrm{M}$ sulfuric acid and product quantitated by optical density at $450 \mathrm{~nm}$. No endogenous activity was observed in any of the cell lines tested. Control reactions in which primary antibody was omitted were performed on all cell lines and found to be negligible.

\subsubsection{Immunocytochemistry}

Immunocytochemical studies were performed on primary cultures and immortalised cells which were seeded onto plastic Nunc LabTek chamber slides (Gibco, Paisley) and grown to confluence. Surface antigen detection (ICAM-1, VCAM-1, PECAM-1, GLUT-1, transferrin receptor) was achieved by washing the cells in HBSS and subsequently blocking with HBSS containing $100 \mu \mathrm{g} / \mathrm{ml}$ normal rabbit IgG and $4 \mathrm{mg} / \mathrm{ml}$ bovine serum albumin. Both omission of the primary antibody and substitution with an isotype-matched $\mathrm{mAb}$ served as controls except for the anti-von Willebrand factor polyclonal $\mathrm{Ab}$ which was substituted with rabbit serum. Primary antibodies were then added to unfixed cells and incubated for $1 \mathrm{~h}$ over ice, washed, and a second anti-species-specific biotinylated or directly conjugated to FITC antibody added for $30 \mathrm{~min}$. With the biotinylated mAb the cells were then washed and the third layer, which consisted of FITC-labelled streptavadin, was incubated with the cells for $15 \mathrm{~min}$. Cells were then washed, fixed, mounted and viewed on a Zeiss
Axiophot (Carl Zeiss, Herts). Internal epitopes were detected by permeabilising the cells with either acetone ( $\mathrm{PgP}$, SV40 antigen) or methanol (von Willebrand factor) at $-20^{\circ} \mathrm{C}$ for $5 \mathrm{~min}$, washed with PBS and treated with antibodies as described above.

\subsubsection{Uptake of acetylated $L D L$}

Primary cultures of brain and retinal endothelial cells and immortalised lines were treated with DiI-acetylated LDL $(10 \mu \mathrm{g} / \mathrm{ml})$ for $4 \mathrm{~h}$ at $37^{\circ} \mathrm{C}$. The cell monolayers were then washed thoroughly and the cells fixed with $3 \%$ formaldehyde and mounted and viewed under standard rhodamine excitation/emission filters on a Zeiss Axiophot microscope.

\subsubsection{Flow cytometry}

Flow cytometry of brain or retinal endothelial cell or RPE cultures was performed on a FACScan (Becton-Dickinson FACScan, Oxford). After washing, cell monolayers were dissociated in HBSS containing $1 \mathrm{mg} / \mathrm{ml}$ collagenase/dispase and $0.2 \%$ EDTA and cells resuspended in phosphate buffered saline. $5 \times 10^{4}$ cells per vial were incubated for $1 \mathrm{~h}$ on ice with primary antibodies against surface expressed epitopes followed by a further $1 \mathrm{~h}$ incubation with FITC conjugated rabbit anti-mouse IgG $\mathrm{F}\left(\mathrm{ab}^{\prime}\right) 2$ antibody (FITC-RAMIG) in the presence of $20 \%$ normal rat serum. After washing twice, cells were resuspended in phosphate buffered saline and analysed. Unstained cells were used to set the parameters, and cells stained with FITC-RAMIG alone were used to set background control. Negative controls were carried out using isotype matched irrelevant antibodies in place of the primary antibody.

In addition, dissociated endothelial cells were incubated for $30 \mathrm{~min}$ with the FITC-labelled lectin Griffonia simplicifolia at a final concentration of $20 \mu \mathrm{g} / \mathrm{ml}$ in PBS supplemented with $0.1 \mathrm{~g} / 1$ of $\mathrm{CaCl}_{2}(\mathrm{pH} 7.4)$ and $10 \%$ FCS. The cells were then washed and resuspended in $20 \%$ FCS-BSA for flow cytometric analysis. Control cells received no lectin.

\subsection{T-lymphocyte transmonolayer migration}

The ability of the immortalised cells to support the transendothelial migration of antigen specific $T$ cells was determined as previously described (Greenwood and Calder, 1993). Briefly, T-cells were added $\left(2 \times 10^{5}\right.$ cells/well) to 24 well plates containing monolayers of primary and immortalised cell cultures of cerebral EC, retinal EC and RPE. T-cells were allowed to settle and migrate over a $4 \mathrm{~h}$ period. To evaluate the level of migration cocultures were placed on the stage of a phasecontrast inverted microscope housed in a temperature controlled $\left(37^{\circ} \mathrm{C}\right), 5 \% \mathrm{CO}_{2}$ gassed chamber (Zeiss). A $200 \times$ $200 \mu \mathrm{m}$ field was randomly chosen and recorded for 10 min spanning the $4 \mathrm{~h}$ time point using a video camera 
linked to a time-lapse video recorder. Recordings were replayed at $160 \times$ normal speed and cells were identified and counted that were on the surface of the monolayer and that had migrated through the monolayer. T-cells on the surface of the monolayer were identified by their highly refractive appearance (phase-bright) and rounded or partially spread appearance. In contrast, cells that had migrated through the monolayer were phase-dark, highly attenuated and were seen to probe under the endothelial cells in a distinctive manner (Greenwood and Calder, 1993; Greenwood et al., 1995; Devine et al., 1996a,b). The data was expressed as the percentage of total lymphocytes within a field that had migrated through the monolayer. A minimum of six wells per assay was performed.

\section{Results}

\subsection{SV40 large $T$ transfection of rat cerebral and retinal endothelia and RPE}

Transfected cells selected by sustained growth in G418 produced parent lines of brain and retinal endothelia which were designated the codes GP8 and JG2, respectively. From these parent lines a number of clones were produced. Using morphological criteria one clone from each parent line was selected for expansion and investigation. The cerebral endothelial clone was designated as GP8.3 and the retinal endothelial clone as JG2.1. The parent cell line of the transfected RPE cells was designated LD7 and the selected clone as LD7.4. Each clone expressed the large T antigen at the permissive temperature (Fig. 1) and was cultured for up to passage 35 without observed differences. In order to establish that SV40 large T-antigen immortalised cells were incapable of producing infective SV40 virus, due to contamination of cells with helper viruses, culture supernatants from GP8.3, JG2.1 and LD7.4 were transferred to subconfluent cultures of wild type mouse Swiss 3 T3 fibroblasts for $4 \mathrm{~h}$. Endothelial and RPE conditioned medium was then removed and fibroblasts cultured for $48 \mathrm{~h}$ in DMEM supplemented with $10 \%$ foetal calf serum. Swiss 3T3 fibroblasts were then seeded into selective media containing $800 \mu \mathrm{g} / \mathrm{ml} \mathrm{G} 418$. No G418 resistant colonies were isolated demonstrating the absence of infective SV40 virus in endothelial and RPE conditioned media. It was independently established that wild type Swiss 3T3 fibroblasts were sensitive to G418 above a concentration of $800 \mu \mathrm{g} / \mathrm{ml}$ but that cells transfected with pSV2neo were insensitive to G418 at $800 \mu \mathrm{g} / \mathrm{ml}$.

\subsection{Endothelial and RPE cell morphology}

Primary cultures of brain and retinal endothelia exhibited spindle shaped morphology characteristic of these cells (Fig. 2). The morphology of the SV40 large T transfected parent lines and clones differed from the primary cultures in that the brain endothelia (GP8.3) were marginally more cobblestone in appearance. The retinal endothelia (JG2.1) retained their spindle-shaped appearance but were slightly more rounded than primary cultures (Fig. 2). The morphology of the transformed RPE cells (LD7.4) were similar to primary cultures but were more regular in shape with less spreading (Fig. 2). Unlike primary cultures, the immortalised cells were not pigmented.
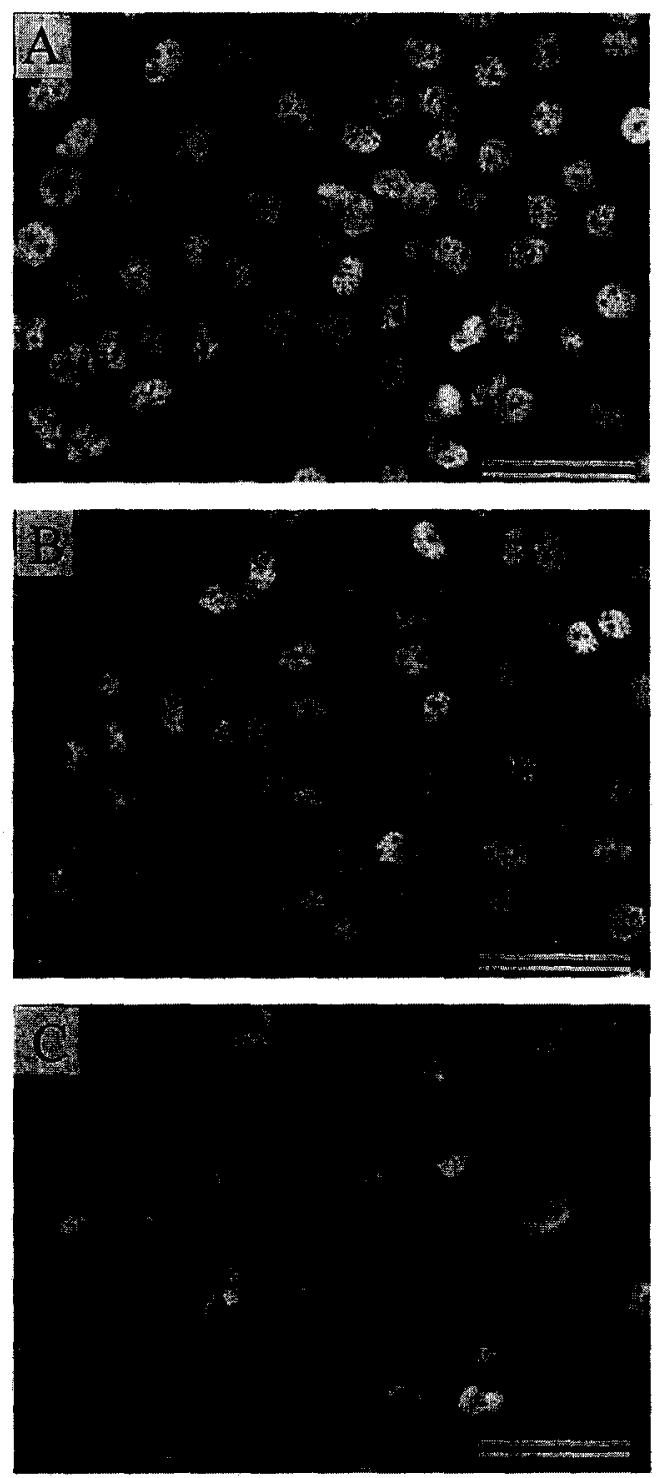

Fig. 1. Immunocytochemical localisation of SV40 large T-antigen in G418 resistant cell clones. (A) SV40 large $T$ immortalised brain endothelial cell clone GP8.3, (B) SV40 large T immortalised rat retinal endothelial cell clone JG2.1, and (C) SV40 large T immortalised RPE cell clone LD7.4. Cells were fixed in $3 \%$ paraformaldehyde, permeabilised and stained with mouse anti-large $\mathrm{T}$-antigen $\mathrm{IgG}$ followed by anti-mouseFITC. No staining was observed when the primary $A b$ was omitted or when substituted with an irrelevant isotype-matched control. Bar $=50$ $\mu \mathrm{m}$. 


\subsection{Expression of endothelial, CNS-endothelial and RPE markers}

Primary cultures of brain and retinal endothelium, T-antigen expressing parent lines and derived clones showed constitutive expression of the CNS-endothelial specific markers P-glycoprotein, GLUT-1 and the transferrin receptor which was not expressed on aortic endothelium (Table 1). In contrast, the phenotype-discriminating $\mathrm{OX}-43 \mathrm{mAb}$ which is normally only found on peripheral endothelia was expressed on aortic endothelia but not by either primary cultures or immortalised CNS-derived endothelial cells (Table 1). In addition, primary cultures and immortalised cultures of both rat brain and retinal endothelia were positive for von Willebrand factor (Table 1; Fig. 3) and the rat endothelial-specific antigen RECA-1 (Table 1; Fig. 4). Similarly the lectin Griffonia simplicifolia, which binds to endothelia (Roux et al., 1994), bound to both primary and immortalised endothelial cells (Fig. 4).

Both primary cultures of RPE and the immortalised RPE clone LD7.4 were positive for the RPE specific antigen RET-PE2 although the level of expression in the primary cultured cells was an order of magnitude higher (Fig. 5). Furthermore, the expression of cytokeratins, which are commonly used to identify RPE cells, were found to be present to the same degree in both primary and immortalised cells as assessed by flow cytometric analysis (Fig. 5).
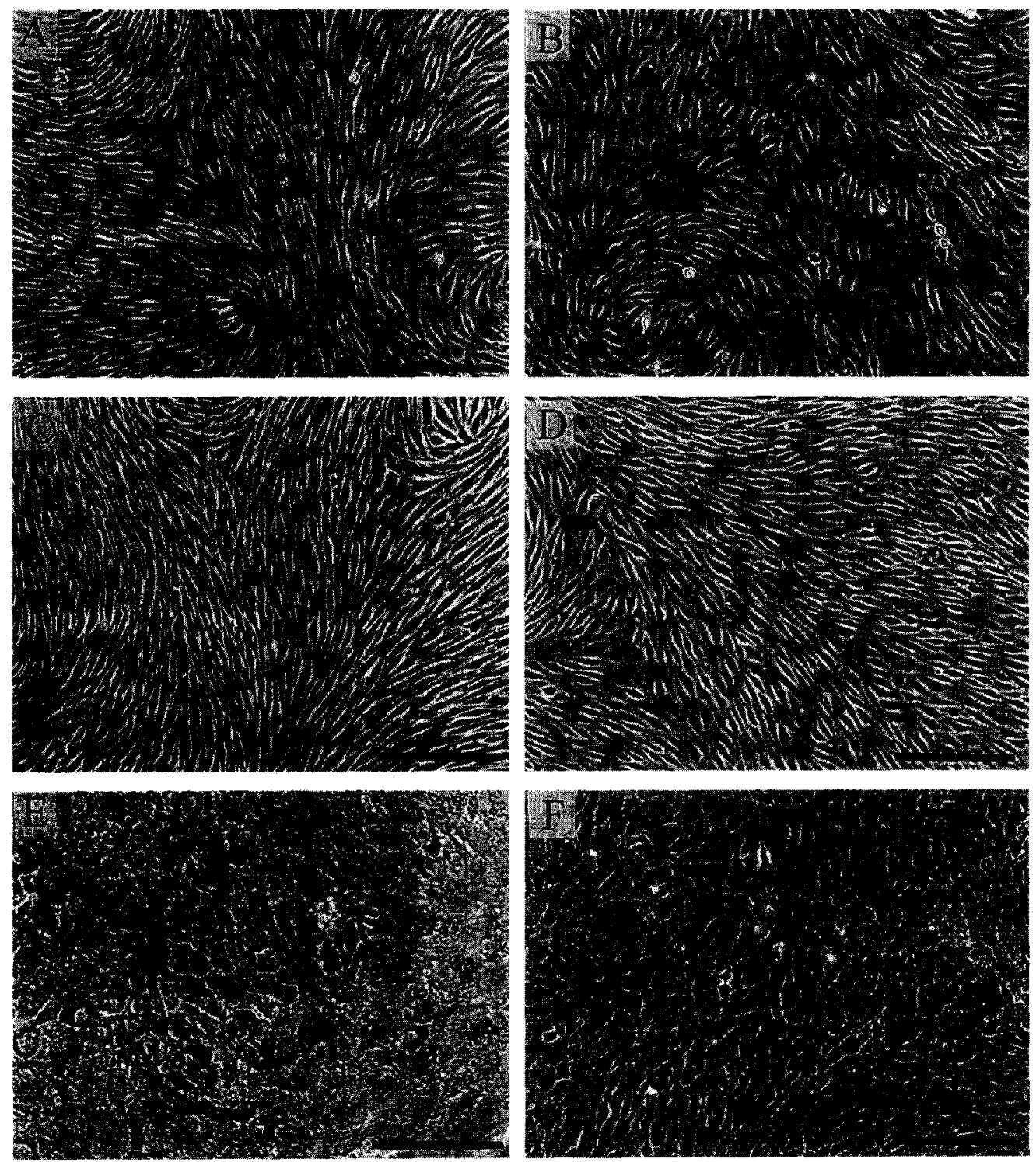

Fig. 2. Morphology of primary cultures and G418 resistant clones of rat CNS endothelial and RPE cells. (A) Primary culture of rat brain endothelial cells. (B) SV40 large T immortalised rat brain endothelial cell clone GP8.3. (C) Primary culture of rat retinal endothelial cells. (D) SV40 large T immortalised rat retinal endothelial cell clone JG2.1. (E) Primary culture of rat RPE cells. (F) SV40 large T immortalised RPE cell clone LD7.4. Bar $=200 \mu$ m. 


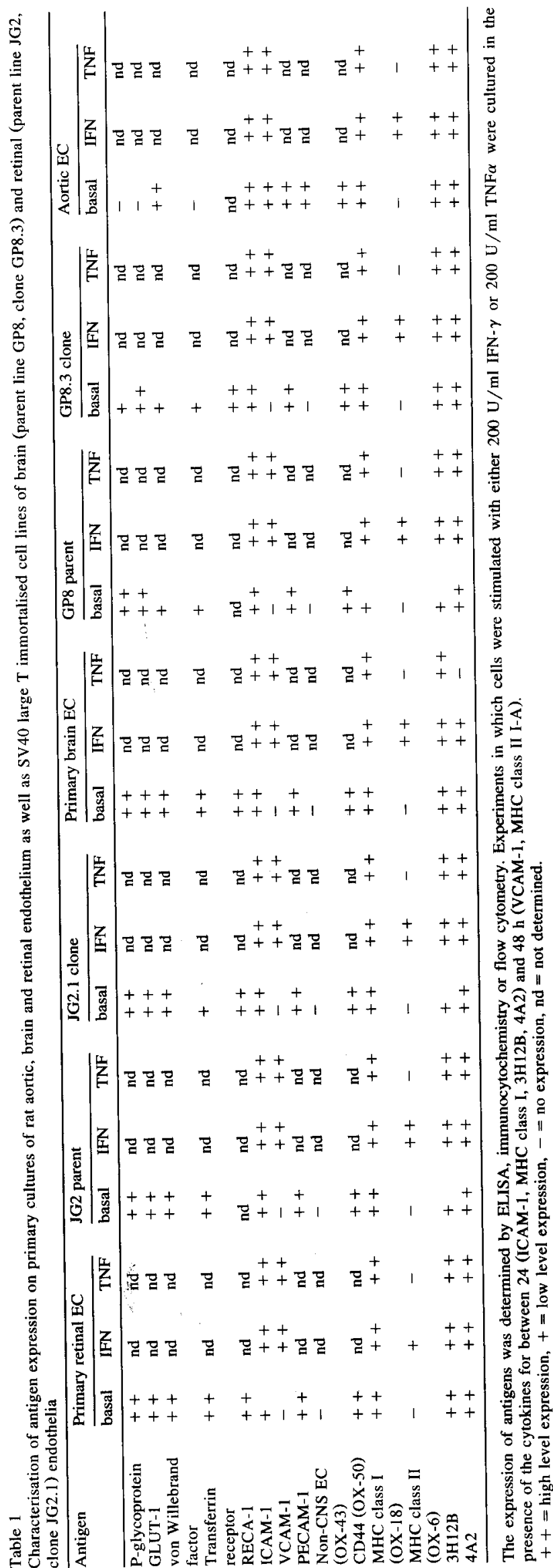




\subsection{Endothelial cell uptake of acetylated $L D L$}

Primary cultures of both brain and retinal endothelia, and the immortalised cell clones GP8.3 and JG2.1 exhibited uptake of acetylated LDL (Fig. 3).

\subsection{Expression of endothelial antigens on primary cul- tures and immortalised lines}

Primary cultures of both brain and retinal endothelia, and immortalised cells derived from these cultures were screened against a panel of brain-endothelial positive antibodies originally raised against microglial cells (Flaris et al., 1993) and subsequently found to bind to brain endothelial cells (Male et al., 1995). All antigens were strongly expressed by primary cultures of rat brain endothelia, with some reduction in antigen expression after immortalization with the antibodies $2 \mathrm{H} 4$ and $1 \mathrm{~A} 8 \mathrm{~B}$ (Table 2). There was also reduced expression of $4 \mathrm{C} 6 \mathrm{C}$ on the GP8 parent line and $3 \mathrm{~B} 7$ on the GP8.3 clone. With the immortalized retinal endothelial cells there was a reduced expression of $3 \mathrm{~B} 7$ and 4C6C compared to primary cultured cells. The antigens $1 \mathrm{Cl}$ and $1 \mathrm{D} 2$ were strongly expressed on primary cultures of brain and retinal endothelia but were not de- tected on the immortalized parent lines and clones (Table 2). Of particular interest was the lack of expression of the $1 \mathrm{~A} 8 \mathrm{~B}$ antigen on both primary cultures and immortalized cells of retinal endothelia.

\subsection{Expression of major histocompatibility antigens}

All endothelial and RPE cultures showed some constitutive expression of MHC class I (OX-18) (Table 1; Figs. 4 and 6) which was upregulated by treatment with 100 $\mathrm{U} / \mathrm{ml}$ rat recombinant $\mathrm{IFN}-\gamma$ for $24 \mathrm{~h}$ (Fig. 6; Table 1). Primary cultures of brain and retinal EC as well as all $\mathrm{T}$-antigen expressing parent lines and clones showed negligible constitutive expression of MHC class II (Table 1; Fig. 4). However, cultures of endothelia treated for $48 \mathrm{~h}$ with $200 \mathrm{U} / \mathrm{ml}$ rat recombinant IFN- $\gamma$, but not $200 \mathrm{U} / \mathrm{ml}$ TNF $\alpha$, showed strong induction of MHC class II I-A (OX-6) (Table 1). Both primary and immortalised RPE cells also expressed negligible MHC class II I-A or MHC class II I-E but following IFN- $\gamma$ activation $(100 \mathrm{U} / \mathrm{ml})$ of the LD7.4 clone I-A was increased significantly after 1 day $(p<0.05)$ and I-E after 2 days $(p<0.05)$, both increasing in their level of expression to day $5(P<0.001$ and 0.005 , respectively) (Figs. 6 and 7). This level of response was comparable with primary RPE cells (data not shown).
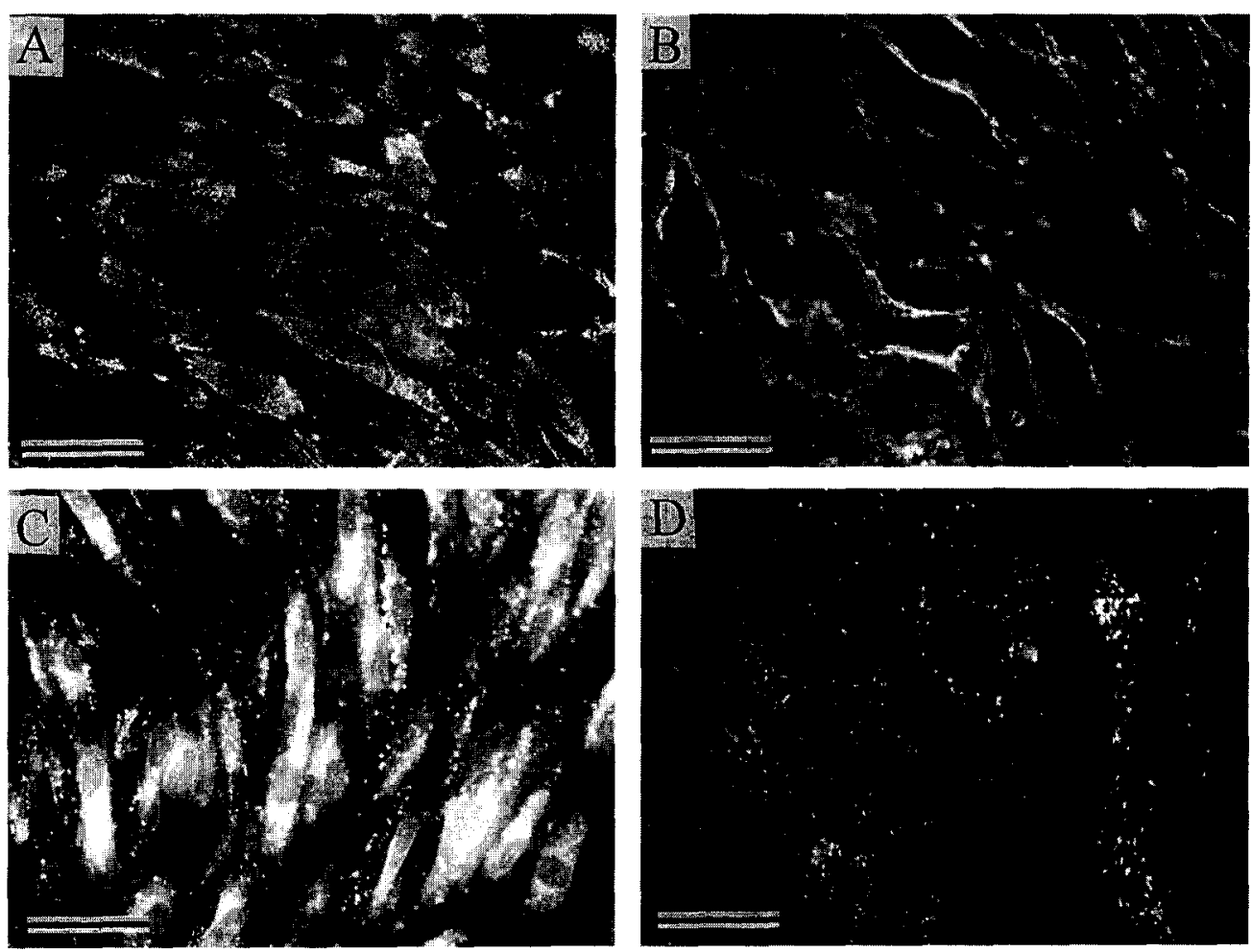

Fig. 3. Fluorescent light micrographs of (A) rat brain endothelial cell clone GP8.3 expression of ICAM-1 stained with anti-ICAM-1 mAb $1 \mathrm{~A} 29 . \mathrm{Bar}=50$ $\mu \mathrm{m}$. (B) Rat brain endothelial cell clone GP8.3 expression of PECAM-1 stained with anti-PECAM-1 mAb 3A12. Bar $=50 \mu \mathrm{m}$. (C) Rat retinal endothelial cell clone JG2.1 uptake of Dil-labelled acetylated LDL. Bar $=50 \mu \mathrm{m}$. (D) Rat retinal endothelial cell clone JG2.1 expression of von Willebrand factor stained with cross-reactive anti-human von Willebrand factor polyclonal Ab. Bar $=20 \mu \mathrm{m}$. No staining was observed when the primary Ab was omitted or when substituted with an irrelevant isotype-matched control. 

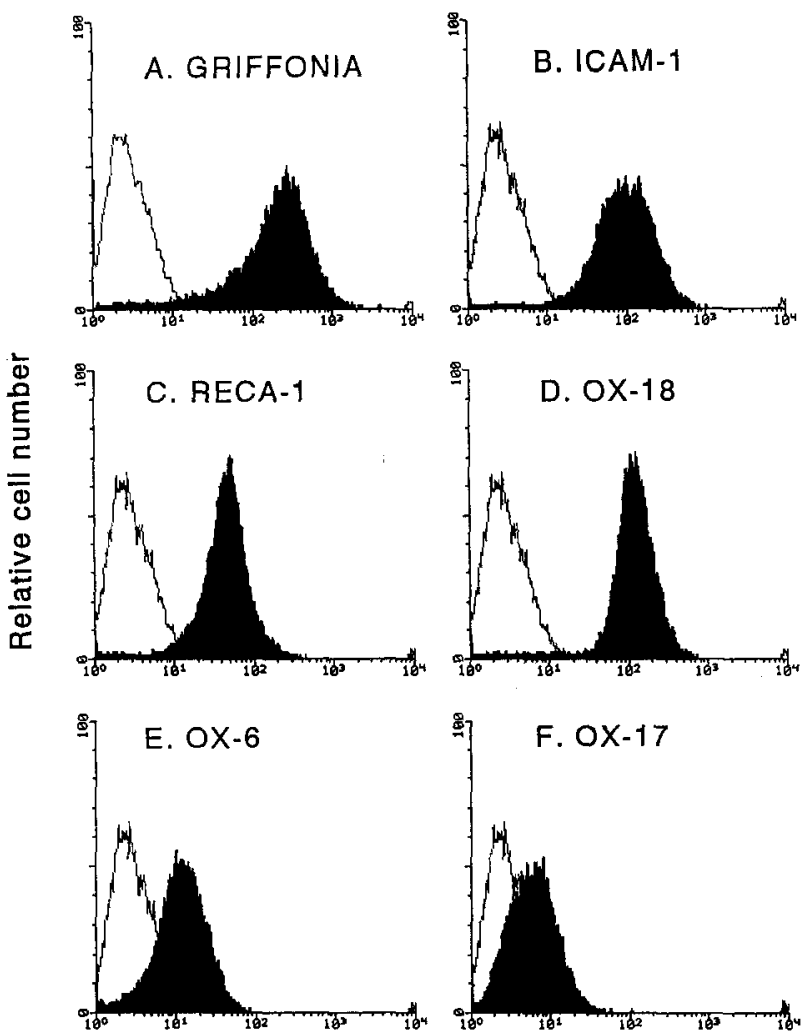

Fluorescence intensity (log)

Fig. 4. Flow cytometric analysis of untreated SV40 large T immortalised rat brain endothelial cell clone GP8.3. Cells were stained with (A) Griffonia simplicifolia lectin, (B) ICAM-1, (C) rat endothelial cell specific marker RECA-1, (D) OX-18 (MHC class I), (E) OX-6 (MHC class II I-A), and (F) OX-17 (MHC class II I-E). FITC-RAMIG controls are shown in each case as open histograms. No positive staining was observed with isotype-matched irrelevant antibody controls.
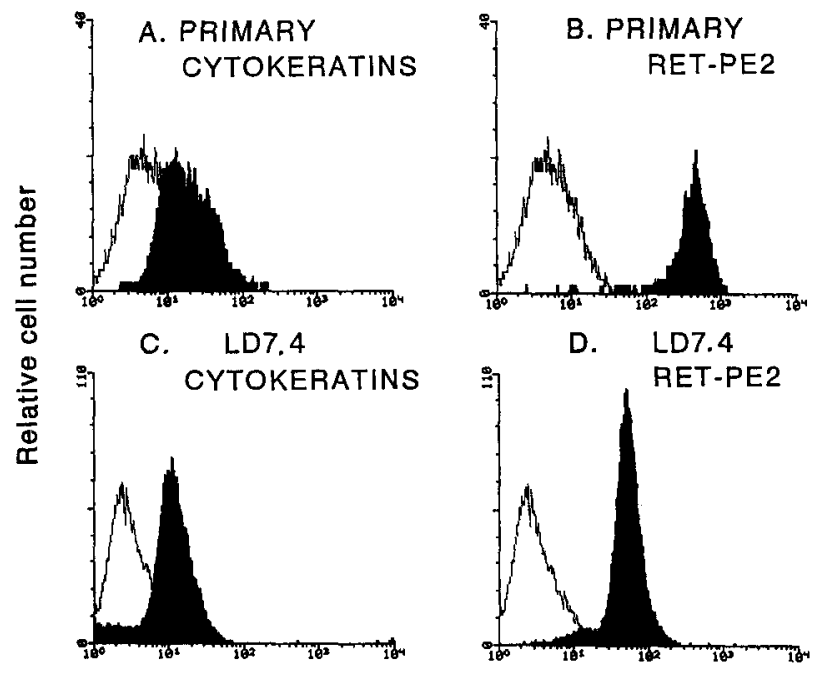

Fluorescence intensity (log)

Fig. 5. Flow cytometric analysis of cytokeratins and the RET-PE2 antigen on primary cultures of RPE and SV40 large T immortalised RPE cell clone LD7.4. Cytokeratin staining on (A) primary culture RPE cells and (C) LD7.4 RPE cell line. RET-PE2 expression on (B) primary culture RPE cells and (D) LD7.4 RPE cell line. FITC-RAMIG controls are shown in each case as open histograms. No positive staining was observed with isotype-matched irrelevant antibody controls.

\subsection{Expression of immunoglobulin family adhesion molecules}

Endothelial and RPE cell cultures constitutively expressed ICAM-1 (assessed using 1A29 $\mathrm{mAb}$ and $3 \mathrm{H} 8$ antisera) which could be further augmented by treatment with $100 \mathrm{U} / \mathrm{ml} \mathrm{IFN-} \gamma$ or $100 \mathrm{U} / \mathrm{ml} \mathrm{TNF} \alpha$ for $24 \mathrm{~h}$ (Table 1; Figs. 3, 4 and 6). Primary cultures of endothelial cells, RPE cells and all T-antigen expressing cells showed no basal expression of VCAM-1 (5F10). VCAM-1 was

Table 2

Expression of surface antigens on primary and SV40 large T immortalised cell lines of brain (parent line GP8, clone GP8.3) and retinal (parent line JG2, clone JG2.1) endothelia

\begin{tabular}{|c|c|c|c|c|c|c|c|}
\hline Antigen & Primary retinal EC & JG2 parent & JG2.1 clone & Primary brain EC & GP8 parent & GP8.3 clone & Aortic EC \\
\hline $3 \mathrm{~B} 7$ & ++ & + & + & ++ & ++ & + & ++ \\
\hline 3D11 & ++ & ++ & ++ & ++ & ++ & ++ & ++ \\
\hline $3 \mathrm{D} 7 \mathrm{~B}$ & ++ & ++ & + & ++ & ++ & ++ & ++ \\
\hline $4 \mathrm{C} 6 \mathrm{C}$ & ++ & + & + & ++ & + & ++ & ++ \\
\hline $2 F 1 B$ & ++ & ++ & ++ & ++ & ++ & ++ & ++ \\
\hline $2 \mathrm{H} 4$ & + & + & + & ++ & + & + & ++ \\
\hline $4 \mathrm{E} 3$ & $+t$ & ++ & ++ & ++ & ++ & ++ & ++ \\
\hline $2 \mathrm{~A} 5$ & ++ & ++ & ++ & ++ & ++ & ++ & ++ \\
\hline $1 \mathrm{~A} 8 \mathrm{~B}$ & - & - & - & ++ & + & + & ++ \\
\hline $1 \mathrm{Cl}$ & ++ & - & - & $+t$ & - & - & ++ \\
\hline $1 \mathrm{C} 11$ & ++ & ++ & $+t$ & ++ & ++ & ++ & ++ \\
\hline $1 \mathrm{D} 2$ & ++ & - & - & ++ & - & - & ++ \\
\hline 4E8.C4 & ++ & ++ & ++ & ++ & ++ & ++ & ++ \\
\hline
\end{tabular}

All antigens have previously been shown to be expressed on rat brain endothelium. Cells were plated onto 96 wells and were cultured for 3 days after which they were fixed and the antigen expression determined using ELISA.

$++=$ high level expression, $+=$ low level expression, $-=$ no expression. 
UNTREATED LD7.4

A. ICAM-1

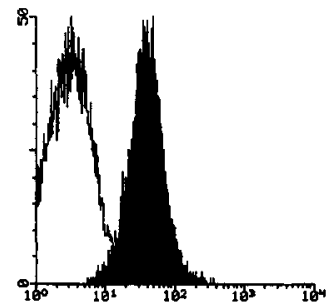

C. $0 X-18$
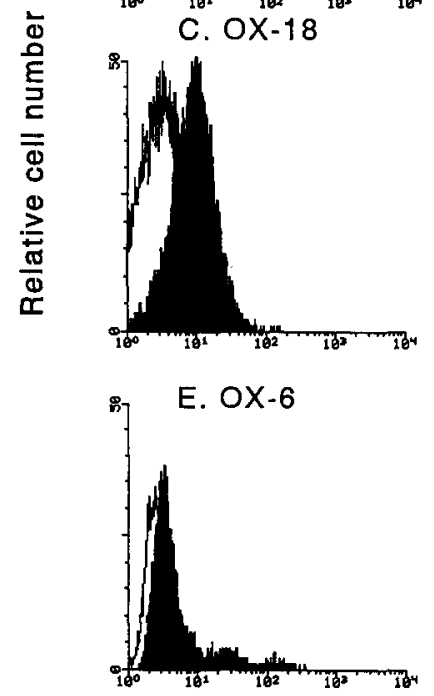

IFN ACTIVATED

B. ICAM-1

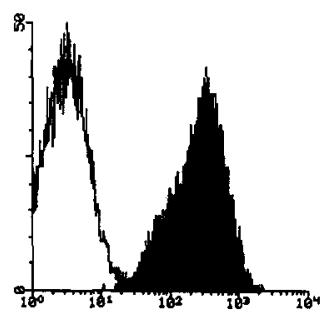

D. OX-18

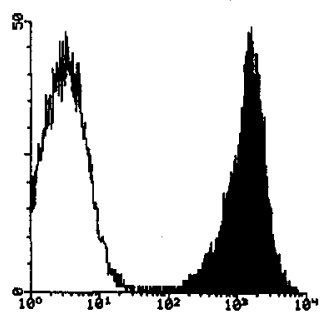

F. OX-6

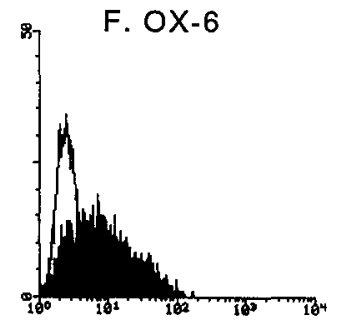

Fluorescence intensity (log)

Fig. 6. Flow cytometric analysis of ICAM-1, MHC class I (OX-18) and MHC class II I-A (OX-6) on untreated SV40 large T immortalised RPE cell clone LD7.4 (A, C and E) and cells activated for $24 \mathrm{~h}$ with 100 $\mathrm{U} / \mathrm{ml} \mathrm{IFN-} \gamma$ (B, D, and F). FITC-RAMIG controls are shown in each case as open histograms. No positive staining was observed with isotypematched irrelevant antibody controls.

induced in both primary cultures of retinal and brain endothelial cells and $\mathrm{T}$-antigen expressing derivatives after treatment for 24 or $48 \mathrm{~h}$ with $200 \mathrm{U} / \mathrm{ml} \mathrm{IFN}-\gamma$ or 200 $\mathrm{U} / \mathrm{ml} \mathrm{TNF} \alpha$ but was noticeably stronger at $48 \mathrm{~h}$. Primary and immortalised RPE cell cultures did not constitutively express VCAM-1 but after 2-5 days of activation with IFN- $\gamma$ showed low levels of expression (Fig. 7). All endothelia were positive for PECAM-1 which was preferentially expressed at the margins of the cell (Table 1; Fig. $3)$.

\subsection{T-lymphocyte transmonolayer migration}

There was no significant difference in the ability of primary or immortalised brain and retinal endothelia to support Ag-specific $\mathrm{T}$ cell line migration. The degree of migration through the monolayers over a $4 \mathrm{~h}$ assay was $52 \pm 5 \%$ for primary brain endothelia; $55 \pm 7 \%$ brain endothelial clone GP8.3; $48 \pm 4 \%$, primary retinal endothelia; $54 \pm 6 \%$ for the retinal endothelial clone JG.1 (Fig. 8). The migration through primary and immortalised RPE cell
A.

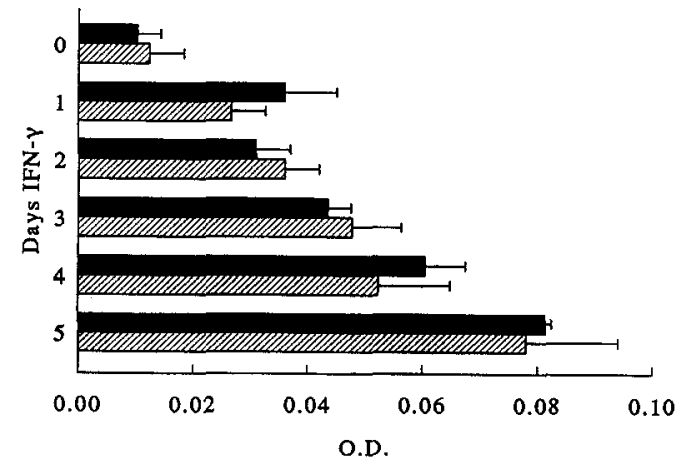

B.

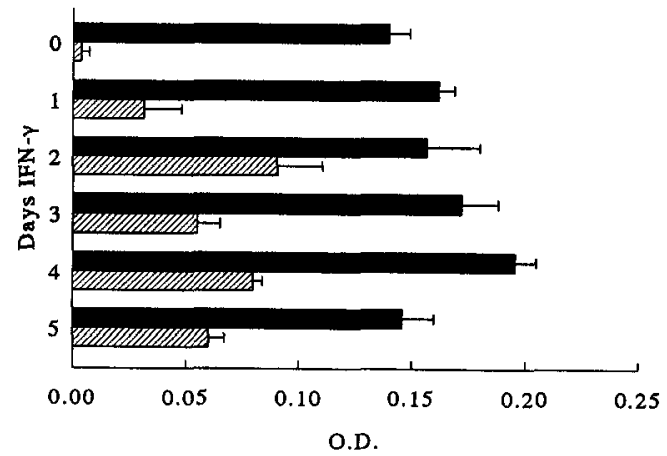

Fig. 7. ELISA analysis of SV40 large $T$ immortalised RPE cell clone LD7.4. (A) Time course of expression of MHC class II I-A (solid bars) and I-E (hatched bars) following treatment of cells with $100 \mathrm{U} / \mathrm{ml}$ IFN- $\gamma$. A significant increase in I-A was observed by $24 \mathrm{~h}(p<0.05)$ and reached a maximum by day $5(p<0.001)$ whereas the increase in I-E reached significance by day $2(p<0.05)$ and was maximal at day 5 $(p<0.005$ ). (B) Time course of expression of ICAM-1 (solid bars) and VCAM-1 (hatched bars) following treatment of cells with $100 \mathrm{U} / \mathrm{ml}$ IFN- $\gamma$. ICAM-1 levels were increased but only reached significance after 4 days $(p<0.001)$ whereas VCAM-1 expression was significantly increased after $24 \mathrm{~h}(p<0.01)$ and remained up to day 5. Means \pm s.e.m.

monolayers, however, differed with a greater degree of migration through primary cells $(38 \pm 3 \%)$ than the immortalised clone LD7.4 $(17 \pm 2 \%, p<0.01)$.

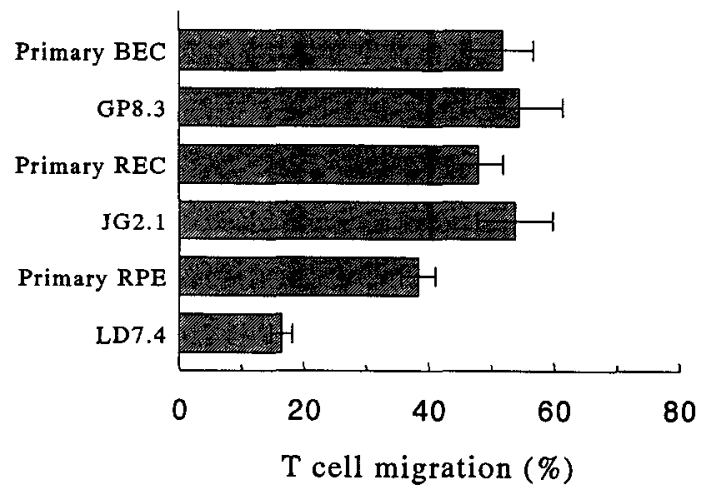

Fig. 8. Migration of an antigen-specific $\mathrm{CD}^{+} \mathrm{T}$ cell line through monolayers of primary cultures of rat CNS endothelium and RPE compared with their corresponding immortalised cell line. Transendothelial migration of T-cells was assessed using time lapse video microscopy after $4 \mathrm{~h}$ of coculture. 


\section{Discussion}

The infection of primary cultures of both rat brain and retinal endothelial cells and rat RPE cells with a recombinant retrovirus encoding the SV40 large T-antigen and a selectable neomycin resistance marker has generated G418-resistant parent cell lines and cell clones which express the large $T$ antigen. In contrast to human cells where transfection of the SV40 large T antigen has been reported to only result in an extended life span of umbilical vein endothelial cell cultures (Fickling et al., 1992), rodent cells appear to be truly immortalised and appear stable in long-term culture (Jat et al., 1986). Immortalised cells derived from primary cultures of brain and retinal endothelial cells as well as RPE retained a similar morphology to primary culture cells, were growth-factor and anchorage-dependent and exhibited contact inhibition. These properties resemble rodent cells transformed with the polyoma large $\mathrm{T}$-antigen but contrasts with rodent cells immortalised with the polyoma middle $\mathrm{T}$-antigen which appear morphologically altered and are highly tumouragenic (Jat et al., 1986). The endothelial cell lines and clones have been maintained for up to 35 passages and express all of the markers ubiquitous to endothelia as well as specific markers characteristic of CNS endothelia. Although there are fewer specific markers for RPE, the RPE cell lines and clones also expressed both cytokeratins and the rat RPE-specific epitope RET-PE2 (Neill and Barnstable, 1990). The major difference observed between primary and transformed RPE cultures was the loss of pigment, which has also been reported previously for a spontaneously arising immortal RPE cell line (McLaren et al., 1993) and an SV40 large T immortalised line (Nabi et al., 1993). However, it is observed that primary cultures of RPE normally lose pigmentation as cells grow out from the heavily pigmented central plaque. Although no pigment could be detected in the RPE clone at the light microscopy level, dark bodies were observed ultrastructurally which resembled premelanosomes.

A major criticism of using cultures of CNS-derived endothelia has been their impurity and phenotypic instability even during short-term culture. This has presented a major problem in generating large numbers of cells of high purity, in particular for immunological and molecular investigations. This problem, and that imposed by both time and financial constraints and the difficulty in generating primary cultures, suggests that the use of immortalised cell lines would greatly facilitate research into these specialised endothelia. It has been argued that primary cultures of these cells do not fully represent their in vivo counterparts and thus the immortalisation of these cells is likely to lead to cell lines that are even less representative. Although this may be true for some functions, providing there is retention of the properties of interest, we propose that such lines will provide the necessary purity and biomass often required for biochemical, immunological and molecular analysis. With the brain and retinal endothelial cell lines we have shown that none of the characteristic markers investigated so far have been lost. Similarly, although there are fewer markers available for the RPE cells, these cells have also maintained their phenotype. Indeed, in recent investigations we have demonstrated that the immortalised RPE cell line LD7.4 when injected subretinally in the RCS rat produce functional RPE monolayers capable of supporting photoreceptor function (Litchfield et al., 1996).

In this study we have also undertaken preliminary investigations into the immunological functions of the cell lines. We have investigated the ability of these cell lines to support antigen specific $T$ cell line migration. Previous studies in our laboratory have shown that $\mathrm{T}$ cell lines, but not mitogen activated peripheral lymph node cells, are able to migrate across primary cultures of CNS-derived endothelial (Greenwood and Calder, 1993) and RPE monolayers (Devine et al., 1996a). On non-activated monolayers this process is mediated predominantly by the interaction between LFA-1 on the lymphocytes and ICAM-1 on the endothelia and RPE (Greenwood et al., 1995; Devine et al., 1996b). The migration of antigen-specific $T$ cell lines across monolayers of GP8.3 and JG2.1 endothelial cells was identical to that obtained with primary cultures of rat brain and retinal endothelia. Although antibody blockade studies have not been carried out it is reasonable to suggest that as the immortalised cells express ICAM-1 to a similar level as on primary culture endothelia, that lymphocyte migration across these monolayers may also be mediated by the LFA-1/ICAM-1 interaction. The migration of $\mathrm{T}$ cell lines through LD7.4 RPE monolayers, however, was significantly lower than across primary cultures. The reasons for this are at present unclear as the immortalised cells express similar levels of ICAM-1. However, the uniformity and closer packing of the immortalised cells may provide a greater physical barrier for the lymphocytes to migrate across. In support of this, preliminary data from our laboratory would suggest that monolayers of LD7.4 RPE cells are capable of maintaining a high transmonolayer electrical resistance.

As these cells are also able to express other immunologically important molecules such as VCAM-1, PECAM-1 and the major histocompatibility complex (MHC) class I and class II (I-A) molecules, they may prove to be invaluable cell lines for investigating the immunological properties of these specialised endothelia (Calder and Greenwood, 1995). Both the constitutive and temporal sequence of MHC class I, MHC class II, ICAM-1, PECAM-1 and VCAM-1 expression following IFN- $\gamma$-activation of the immortalised endothelium and RPE was similar to that observed for primary cultures. We are currently using these cells to investigate signal transduction via endothelial cell ICAM-1 (Adamson et al., 1995) and its role in facilitating lymphocyte migration. It has already been reported using the RBE4 cell line that signal transduction through 
the ICAM-1 molecule leads to tyrosine phosphorylation of actin binding proteins (Durieu-Trautmann et al., 1994). An advantage of the cell lines we have generated over those of the RBE4 cell line is that the SV40 large T-antigen contains temperature sensitive mutation (tsa58) which results in the large T-antigen being degraded when cells are cultured at temperatures over $37.5^{\circ} \mathrm{C}$ which will allow the expression of the large $\mathrm{T}$-antigen to be switched off. This may be a significant advantage in some investigations.

A further recent development using immortalised endothelial cells has been their use as vectors for gene therapy to neoplasms of the CNS (Lal et al., 1994). Cells expressing the lac- $\mathrm{Z}$ reporter gene have been intracranially reintroduced into experimental rat gliomas. These genetically modified endothelial cells incorporate into the host tissue and particularly into the host vasculature providing a novel opportunity for endothelial cell implantation to be used as a means of delivering therapeutic genes to CNS neoplasms. This approach may be extended for other CNS disorders and, as has already been mentioned, we have carried out preliminary investigations into the therapeutic use of the RPE cell clone LD7.4 in an experimental model of retinal macular degeneration (Litchfield et al., 1996).

The screening of the immortalised endothelial cells with a panel of antibodies known to stain brain endothelial cells in tissue section has revealed an interesting finding. The antibody $2 \mathrm{~A} 4$ was found to be expressed on brain endothelia but not on primary cultures or immortalised lines of retinal endothelia. To date, we have not been able to detect any difference between endothelia from these two sites within the CNS and this finding is the first that appears to demonstrate a difference between the two vascular endothelia. We are currently exploring these differences further.

It is unlikely that the immortalised cells described here or the RBE4 cell line will completely replace the need for primary cultures as it will be important to characterise these cells for each investigation. However, the availability of these cells, particularly when large numbers of cells are needed as for genetic manipulation or immunological and molecular analysis, should prove invaluable for future research into the cells that constitute the $\mathrm{BBB}$ and $\mathrm{BRB}$.

\section{References}

Abbott, N.J., Hughes, C.C.W., Revest, P.A and Greenwood, J. (1992) Development and characterisation of a rat brain capillary endothelial culture: Towards an in vitro blood-brain barrier. J. Cell. Sci. 103, 23-37.

Abbott, N.J., Couraud, P-O., Roux, F. and Begley, D.J. (1995) Studies on an immortalised brain endothelial cell line: Characterization, permeability and transport. In: J. Greenwood, D. Begley and M. Segal (Eds.), New Concepts of a Blood-Brain Barrier. Plenum, New York, pp. 239-249.

Adamson, P., Couraud, P.-O., Durieu-Trautmann, O. and Greenwood, J. (1995) ICAM-I mediated signalling in CNS endothelial cells. Immunology 86 , Suppl. 1, 44
Bourdoulous, S., Béraud, E., Le Page, C., Zamora, A.J., Ferry, A., Bernard, D., Strosberg, A.D. and Couraud, P.-O. (1995) Anergy induction in encephalitogenic $\mathrm{T}$ cells is inhibited by interleukin- 1 . Eur. J. Immunol. 25, 1176-1183.

Butt, A.M. and Jones, H.C. (1992) Effect of histamine and antagonists on electrical resistance across the blood-brain barrier in rat brain-surface microvessels. Brain Res. 569, 100-105.

Calder, V. and Greenwood, J. (1995). Role of the vascular endothelium in immunologically-mediated neurological disease. In: C. Savage and J. Pearson (Eds.), Immunological Aspects of the Vascular Endothelium. Cambridge University Press, Cambridge, pp. 96-121.

Chang, C.W., Roque, R.S., Defoe, D.M. and Caldwell, R.B. (1991) An improved method for isolation and culture of pigment epithelial cells from rat retina. Curr. Eye Res. 10, 1081-1086.

Crone, C. and Olesen, S.-P. (1982) Electrical resistance of brain microvascular endothelium. Brain Res. 241, 49-55.

Devine, L., Lightman, S. and Greenwood, J. (1996a) Lymphocyte migration across the anterior and posterior blood-retinal barrier in vitro. Cell. Immunol. 168, 267-275.

Devine, L., Lightman, S.L. and Greenwood, J. (1996b) Role of LFA-1, ICAM-1, VLA-4 and VCAM- 1 in lymphocyte migration across retinal pigment epithelial monolayers in vitro. Immunology 88, 456-462.

Duijvestijn, A.M., Van Goor, H., Klatter, F., Majoor, G.D, Van Bussel, E. and Van Breda-Vriesman, P.J.C. (1992) Antibodies defining rat endothelial cells: RECA-1, a pan-endothelial cell-specific monoclonal antibody. Lab. Invest. 66, 459-466.

Durieu-Trautmann, O., Chaverot, N., Cazaubon, S., Strosberg, A.D. and Couraud, P.O. (1994) Intercellular adhesion molecule-1 activation induces tyrosine phosphorylation of the cytoskeleton-associated protein cortactin in brain microvessel endothelial cells. J. Biol. Chem. $269,12536-12540$.

Fickling, S.A., Tooze, J.A. and Whitley, G.S.J. (1992) Characterisation of human umbilical vein endothelial cell lines produced by transfection with the early region of SV40. Exp. Cell. Res. 201, 517-521.

Flaris, N.A., Densmore, T.L., Molleston, M.C. and Hickey, W.F. (1993) Characterization of microglia and macrophages in the central nervous system of rats: Definition of the differential expression of molecules using standard and novel monoclonal antibodies in normal CNS and four models of parenchymal reaction. Glia 7, 34-40.

Greenwood, J. (1991) Astrocytes, cerebral endothelium and cell culture: The pursuit of an in vitro blood-brain barrier. Ann. NY Acad. Sci. USA $633,426-431$.

Greenwood, J. (1992a) Experimental manipulation of the blood-brain and blood-retinal barriers. In: M.W.B. Bradbury (Ed.), Handbook of Experimental Pharmacology. Physiology and Pharmacology of the Blood-Brain Barrier, Vol. 103. Springer-Verlag, Berlin, pp. 459-486.

Greenwood, J. (1992b) Characterization of a rat retinal endothelial cell culture and the expression of P-glycoprotein in brain and retinal endothelium in vitro. J. Neuroimmunol. 39, 123-132.

Greenwood, J. and Calder, V. (1993). Lymphocyte migration through cultured endothelial cell monolayers derived from the blood-retinal barrier. Immunology 80, 401-406.

Greenwood, J., Wang, Y. and Calder, V. (1995) Lymphocyte adhesion and transendothelial migration in the CNS: The role of LFA-1, ICAM-1, VLA-4 and VCAM-1. Immunology 86, 408-415.

Hughes, C.C.W., Male, D.K. and Lantos, P.L. (1988) Adhesion of lymphocytes to cerebral microvascular cells: Effects of interferon- $\gamma$, tumour necrosis factor and interleukin-1. Immunology 64, 677-681.

Jat, P.S., Cepko, C.L., Mulligan, R.C. and Sharp, P.A. (1986) Recombinant retroviruses encoding simian virus 40 large $T$ antigen and polyomavirus large and middle $\mathrm{T}$ antigens. Mol. Cell. Biol. 6, 12041217.

Joó, F. (1996) Isolated brain microvessels and cultured cerebral endothelial cells in blood-brain barrier research: 20 years on. In: J. Greenwood, D. Begley and M. Segal (Eds.), New Concepts of a Blood-Brain Barrier. Plenum, New York, pp. 229-237.

Lal, B., Indurti, R.R., Couraud, P-O., Goldstein, G.W. and Laterra, J. 
(1994) Endothelial cell implantation and survival within experimental gliomas. Proc. Natl. Acad, Sci. USA 91, 9695-9699.

Litchfield, T., Whiteley, S.J.O., Greenwood, J., Adamson, P. and Lund, R.D. (1996) Grafting $\$ V 40$ transformed rat retinal epithelial cells to the sub-retinal space. Invest. Ophthalmol. Vis. Sci. 37, 593.

Male, D., Pryce, G., Hughes, C. and Lantos. P. (1990) Lymphocyte migration into brain modelled in vitro: Control by lymphocyle activation, cytokines, and antigen. Cell. Immunol. 127, 1-11.

Male, D., Rahman, J., Pryce, G., Tamatani, T. and Miyasaka, M. (1994) Lymphocyte migration into the CNS modelled in vitro: Roles of LFA-1, ICAM-1 and VLA-4. Immunology 81, 366-372.

Male, D.. Rahman, J., Linke, A., Zhan, W. and Hickey, W. (1995) An interferon-inducible molecule on brain endothelium which controls lymphocyte adhesion mediated by integrins. Immunology 84,453 460.

McCarron, R.M., Kempski, O., Spatz, M. and McFarlin, D. (1985) Presentation of myelin basic protein by murine cerebral vascular endothelial cells. J. Immunol. 134, 3100-3103.

McGuire, P.G. and Orkin, R.W. (1987) Isolation of rat aortic endothelial cells by primary explant techniques and their phenotypic modulation by defined substrata. Lab. Invest. 57, 94-105.

McLaren, M.J., Sasabe, T., Li, C.Y., Brown, M.E. and Inana, G. (1993) Spontaneously arising immortal cell line of rat retinal pigmented epithelial cells. Exp. Cell Res. 204, 311-320.

Neill, J.M. and Barnstable, C.J. (1990) Expression of the cell surface antigens RET-PE2 and N-CAM by rat retinal pigment epithelial cells during development and in tissue culture. Exp. Eye Res. 51, 573-583
Nabi, I.R., Mathews, A.P., Cohen-Gould, L., Gundersen, D. and Rodriguez-Boulan, E. (1993) Immortalization of polarized retinal pigment epithelium. J. Cell Sci. 104, 37-49.

Risau, W., Engelhardt, B. and Wekerle, H. (1990) Immune function of the blood-brain barrier: Incomplete presentation of protein (auto-) antigens by rat brain microvascular endothelium in vitro. J. Cell Biol, $110,1757-1766$.

Roux, F., Durieu-Trautmann. O., Chaverot, N., Claire, M., Mailly, P., Bourte, J.M., Strosberg, A.D. and Courud, P-O. (1994) Regulation of gamma-glutamyl-transpeptidase and alkaline phosphatase activities in immortalised rat brain microvessel endothelial cells. J. Cell. Physiol. 159, 101-113.

Sedgwick, J.D., MacPhee, I.A.M. and Puklavec, M. (1989) Isolation of encephalitogenic $\mathrm{CD} 4^{+} \mathrm{T}$ cell clones in the rat. J. Immunol. Meth. $121,185-196$.

Towler, H.M.A., Greenwood, J. and Butt, A.M. (1994) Electrical resistance across the inner blood-retinal barrier in the intact retina of the anaesthetised Lewis rat. J. Physiol. 480, 10-11P.

Wang, Y., Greenwood, J., Calder, V. and Lightman, S. (1993) Lymphocyte adhesion to cultured endothelial cells of the blood-retinal barrier. J. Neuroimmunol. 48, 161-168.

Wang, Y., Calder, V.L., Lightman, S.L. and Greenwood, J. (1995) Antigen presentation by rat brain and retinal endothelial cells. J. Neuroimmunol. 61, 23j-239.

Zhao, Z-S., Calder, V.L., McLauchlan, M. and Lightman, S.L. (1994) Differential lymphokine expression by rat antigen-specific $\mathrm{CD}^{+}{ }^{+} \mathrm{T}$ cell lines with antigen and mitogen. Cell. Immunol. 159, 220-234. 